\title{
Effect of Extraction Conditions for Recovery of Chlorogenic Acid and Flavonoids from Wet Cider Apple Pomace under Subcritical Water
}

\author{
Salis Ibrahim ${ }^{1}$, Regina Santos $^{2} \&$ Steve Bowra ${ }^{3}$ \\ ${ }^{1}$ University for Development Studies, PO Box TL 1350, Tamale, Ghana \\ ${ }^{2}$ University of Birmingham, Edgbaston, Birmingham, B15 2TT, UK \\ ${ }^{3}$ Department of Research and Development, Phytatec (UK) Ltd., Plas Gogerddan, Aberystwyth, SY23 3EB, UK \\ Correspondence: Salis Ibrahim, University for Development Studies, PO Box TL 1350, Tamale, Ghana. Tel: \\ +233-244-222-176. E-mail: isalis@uds.edu.gh
}

\author{
Received: August 23, 2019 \\ Accepted: September 6, 2019 Online Published: September 18, 2019 \\ doi:10.5539/jfr.v8n6p1 \\ URL: https://doi.org/10.5539/jfr.v8n6p1
}

\begin{abstract}
Industrial wet cider apple pomace was subjected to subcritical water mediated hydrolysis in a batch reactor with varying experimental conditions such as solid-to- solvent ratio $(1-8 \% \mathrm{w} / \mathrm{v})$, temperature $\left(100-200{ }^{\circ} \mathrm{C}\right)$ and a residency time $(10-30 \mathrm{~min})$ to understand the effects of the experimental conditions on overall recovery of polyphenolic compounds. Chlorogenic acid and some flavonoids were identified and quantified by high performance liquid chromatography (HPLC-DAD). Higher yields of chlorogenic acid and the flavonoids were obtained between $100-150{ }^{\circ} \mathrm{C}$ for residence time of 20 minutes. Solid-to solvent ratio and temperature played a significant role in the recovery of the polyphenolic compounds $(\mathrm{p}<0.05)$. The results demonstrated that, residence time at a fixed extraction condition was less significant ( $>>0.05)$. However, it was significant for yield of degradation compounds such as protocatechuic aldehyde, 5- HMF and furfural. Subcritical water selectively influenced the chemical structure of the polyphenolic compounds.
\end{abstract}

Keywords: cider apple pomace, chlorogenic acid, flavonoids, subcritical water extraction

\section{Introduction}

Apples (Malus domestica) are extensively cultivated in many moderate temperate regions of the world. The fruits are enjoyed for their taste and flavour but also acknowledged as a good source of antioxidants, vitamins, and dietary fibre (Brendan, 2010). The global annual production in 2010 was approximately $70 \times 10^{6}$ tonnes covering a $4.8 \times 10^{6}$ hectares (FOA, 2011) thus making apples the 4th most cultivated fruit globally next to banana, oranges and grapes.

Apples can be categorised into, culinary, desert and cider apple varieties. Cider apples are distinct from the desert and culinary apples, due to the high content of tannin and their fibroid nature. There are over seventy cider apple varieties recorded in the United Kingdom and about twenty three reported in France (Johansen, 2000). Of the total production of apples, at least $71 \%$ of the fruit is eaten fresh while $20 \%$ is processed into apple juice and cider after fermentation, the balance is used to produce apple purees, spirits and other by-products of apple (Joshi, 1997, Joshi \& Attri, 1991, Kaushal et al., 2002). Apple pomace is the residue generated after juice extraction and is composed of $20-35 \%$ by weight of the original production feedstock. The amount of the pomace generated and its composition will depend on the variety of the apple and the techniques used in extracting the juice (Mahawar et al., 2012). Approximately $9 \times 10^{6}$ tonnes of apple pomace are produced worldwide per the estimation of the amount of apples processed. The use and the amount of pomace vary according to country. China is the largest producer of apple pomace in the world with estimated annual yield of over 3 million tons since 2009 (Yue et al., 2012). In India, approximately 1 million tonnes of apple pomace every year is produced, of which 10,000 tonnes are exploited (Shalini and Gubta, 2010). At least, 80,000 tonnes of pomace are generated in Brazil each year and primarily utilised as animal feed (Vendruscolo et al., 2008). In northern Spain, 20,000 tonnes per annum of the pomace is generated and accounts for a significant proportion of the global cider apples production (Diñeiro García et al., 2009). Apple pomace is a heterogeneous biomass residue consisting of peels, discarded apples, seeds, core, stems and exhausted apple tissue and a potential source of carbohydrate, fibre, polyphenolic compounds and pectin which can serve as valuable feedstock for food, feed, pharmaceutical or 
cosmetic purposes( Cetkovic et al., 2008, Kennedy et al., 1999, Lu \& Foo, 1997, Lu \& Foo, 2000). Apples represent an important source of flavonoids in diets within Europe and the United States. Approximately $22 \%$ of polyphenolics consumed in the United states are derived from apples (Vinson et al., 2001). The major phenolic compounds found in apples include; chlorogenic acids, epicatechins procyanidins, phloridzin and the quercetin conjugate (Bhushan et al., 2008). It has been revealed that different polyphenolic compounds have potential to impede proliferation of cancer cells, control immune and inflammatory response, and defend against oxidation of lipids (Hollman et al., 1997, Liu, 2003). Polyphenolic compounds are grouped into classes according to the number of carbon atoms in the molecule and also their chemical structure and are classified as phenolic acids and flavonoids which represent non-nutrient natural compounds derived from plants. Flavonoids by far constitute the most diverse group of polyphenolic compounds in plants. Ordinarily they are found as glycoside derivatives and over 4000 flavonoids have been documented in plants (Harborne \& Williams, 2000). The list keeps growing because they can be many patterns of substitution of the "hydroxyl, methoxy or glycosyl" groups of the primary structure, to form more complex ones (Véronique, 2005). Flavonoids are soluble in water and can often be extracted directly with water. The backbone molecule of flavonoids contains 15 carbon atoms and have $C_{6}-C_{3}-C_{6}$ structure skeleton with ring $\mathrm{A}$ and $\mathrm{B}$ been phenolic in nature which are linked together by 3 grouped carbons as shown in figure 1.

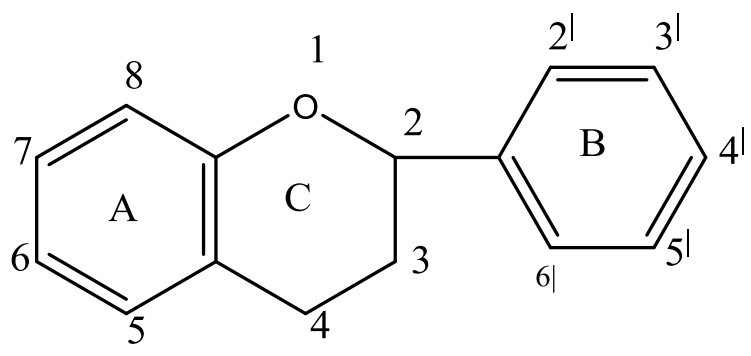

Flavonoid general structure

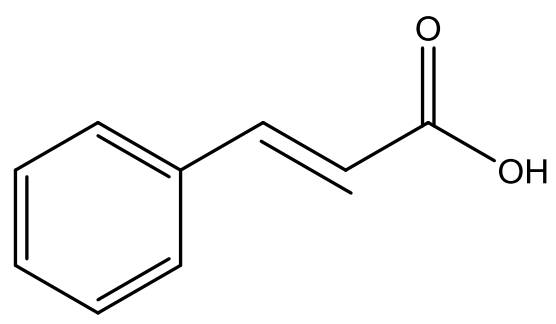

Hydroxycinammic acid structure

Figure 1. general structure for Flavonoids and Phenolic acid

The variations in the chromate ring $\mathrm{C}$ as a result of hydroxylation pattern allow flavonoids to be classified further into six (6) sub-groups; flavonols, flavanols, flavones, flavanones anthocyanin, isoflavones (Scalbert \& Williamson, 2000, Tsao \& McCallum, 2009). Chalcones are also classified as a member of the flavonoids, although they lacked the heterocyclic ring C (Tsao \& McCallum, 2009). Phenolic acids constitute non flavonoids polyphenolic compounds which are further grouped into two main types, as benzoic acid and cinnamic acid derivatives (Manach et al., 2004). Free phenolic acids are obtained from fruits and vegetables but are often in a bound form in grains and seeds and can be freed by acid or alkaline hydrolysis or treatment with enzymes (Adom \& Liu, 2002, Chandrasekara and Shahidi, 2010, Kim et al., 2006). Hydroxycinnamic acids are derived from cinnamic acids and comprised primarily of p-coumaric, caffeic, ferulic and sinapic acids glycosylated derivatives or esters of quinic, shikimic or tartaric acid. Chlorogenic acid which is found in many fruits and in particular coffee is an ester of caffeic and quinic acids. Caffeic acid is the most abundant phenolic acid representing over 75\% of the total of hydrocinnamates in most fruits ( D'Archivio et al., 2007, Manach et al., 2004).

Innovative methods have been explored to recover the polyphenolic compounds from natural sources to reduce the extraction time, the amount of solvent used, and improve yields and quality of extracts (Wang \& Weller, 2006). The traditional solvent extraction methods are often time consuming and require large volumes of solvents (Luque de Castro \& Garcia-Ayuso, 1998). Moreover, the procedure is laborious and produces low selectivity and extraction yield (Ibáñez et al., 2008). However, simply substituting the solvent type usually results in low yields of recovery because of poor solute-solvent affinities and moreover the cost could be higher. Therefore, advanced techniques of extraction with reduced recovery time and organic solvents consumption and increase pollution prevention are required. Subcritical water extractions are perceived as efficient routes to recover polyphenolic compounds from plant matrices. Water is environmentally friendly, non-toxic, easily accessible and inexpensive solvent for the extraction of phytochemicals from plant materials (Çam \& Aaby, 2010). In addition it has been shown that, subcritical water mediated extraction is efficient and can provide higher extraction yields from solid samples (Luque de Castro et al., 1999; Ibrahim et al., 2018). Subcritical water refers to liquid water at a temperature between the atmospheric boiling point and the critical temperature $\left(374^{\circ} \mathrm{C}\right)$ 
of water. The most essential factor to consider in subcritical water procedure is the variation of it dielectric constant. Water at room temperature has a dielectric constant of approximately 80 and decreases to 27 at $250^{\circ} \mathrm{C}$, which is similar to that of ethanol. Therefore by modulating temperature and pressure water can perform like organic solvents solubilising low polarity analytes (Nieto et al., 2010). Moreover the enhancement of extraction efficiency of subcritical water can be attributed to an improvement in the solubility and mass transfer effects as a result of the modification of physico-chemical properties of water at elevated temperature, which also leads to disruption of surface equilibria (Ong et al., 2006). Therefore, the increase in temperature can break the solute-matrix association as a result of van der Waal forces, hydrogen bonding, and dipole attractions of the solute molecules and other active sites in the matrix. Subcritical water has been shown to demonstrate selectivity towards separate groups of compounds at selected temperatures depending on their polarities. Polar compounds are extracted at lower subcritical temperatures whereas less polar ones are recovered at higher temperatures (Ibañez et al., 2003). Water under subcritical conditions has high concentrations of $\mathrm{H}^{+}$and $\mathrm{OH}^{-}$ions which can catalyse acid-base reactions (Arai et al., 2013). Therefore, other water mediated reactions such as hydrolysis and dehydration can occur at the high temperature (Brunner, 2009). The modified physico-chemical properties at the elevated temperature contribute to the disruption of solute-matrix interactions thereby improving solubility and mass transfer effects leading to elution of compounds that are strongly bound to cell wall. The eluted compounds can undergo transformation at the high temperatures to generate other compounds of different chemical properties and structures (Plaza et al., 2010).

The current research assessed the utility of subcritical water in the recovery of chlorogenic acid and selected flavonoids from wet industrial apple pomace with no co-solvents or modifiers added. Different levels of the wet apple pomace were employed to assess the recovery of the phenolic acid and flavonoids under subcritical water conditions. The impact of extraction parameters such as solid-to-solvent ratio, temperature and residence time in a batch reactor under subcritical water mediated operation were investigated to study the relationship between experimental factors and all responses. The composition and structure of the polyphenolics at different temperature levels were determined.

\section{Material and Methods}

\subsection{Chemicals/Reagents}

Phenolic standards comprising, Chlorogenic acid ( $\geq 95 \%), \pm$ Catechin hydrate $(\geq 90 \%)(-)$ Epicatechin $(\geq 90)$, Phloridzin dihydrate $(\geq 99 \%)$, Procyanidin B2 $(\geq 90 \%)$, Quercetin $-3-\beta$-D-glucoside $(\geq 90 \%)$, Quercetin-3-D-galactoside ( $\geq 97 \%$ ), Phloretin, Chromasolv for HPLC water were purchased from Sigma-Aldrich (UK). Acetonenitrile, methanol and glacial acetic acid were obtained from Fisher Scientific (UK).

\subsection{Apple Pomace Sample}

Apple pomace sample was supplied by Universal Beverages Limited (UBL) a subsidiary company of Bulmers, UK. The pomace residue was derived from 7 cider apple varieties comprising Dabinett, Brown Snout, Harry Master Jersey, Chisel Jersey, Vilberie, Michelin, and Yarlinton Mill. The apple pomace residue was very heterogeneous, made-up of peels, seeds, apple flesh and therefore was thoroughly mixed to ensure replicate samples were representative of the population of samples. Portions of the apple pomace were collected for dry weight determination and the rest frozen and then later homogenized for 30 seconds using Moulinex domestic blending machine to minimize variability in batch-to-batch analysis.

Dry weight of the apple pomace was determined using AOCS (American Oil Chemist Society Standard) standard protocol using a laboratory oven (STATUS international, UK) at $103 \pm 3^{\circ} \mathrm{C}$.

\subsection{Experimental Design}

Design of experiments for the subcritical water extraction were done according to (Ibrahim et al., 2018) which were composed of screening experiments and the actual design by response surface methodology (RSM). Screening experiments were conducted to identify effects of dependent variables such as temperature, solid to solvent ratio and residency time on overall recovery of the polyphenolic compounds. The results of the screening experiments were used, with the aid of Stat-Ease Design Expert software 7.0, to construct experiments using the central composite rotatable design (CCRD. Twenty experimental points were generated in all, comprising of 14 trials and 6 replicates runs around the centre point. The extraction programme is shown in Table 1. 
Table 1. Design of experment by Central Composite Rotatable Design (CCRD) using 3 factors under subcritical water extraction

\begin{tabular}{lllll}
\hline \multirow{2}{*}{ Standard } & \multirow{2}{*}{ Run } & Factor 1 & Factor 2 & Factor 3 \\
\cline { 3 - 5 } & & A: Solid/Solvent ratio $\%$ & B: Temp ${ }^{\circ} \mathrm{C}$ & C: Residence time min \\
\hline 20 & 10 & 4.5 & 150.0 & 20.0 \\
19 & 20 & 4.5 & 150.0 & 20.0 \\
18 & 4 & 4.5 & 150.0 & 20.0 \\
17 & 15 & 4.5 & 150.0 & 20.0 \\
16 & 17 & 4.5 & 150.0 & 20.0 \\
15 & 9 & 4.5 & 150.0 & 20.0 \\
14 & 11 & 4.5 & 150.0 & 37.0 \\
13 & 12 & 4.5 & 150.0 & 3.0 \\
12 & 8 & 4.5 & 234.1 & 20.0 \\
11 & 2 & 4.5 & 66.0 & 20.0 \\
10 & 19 & 9.5 & 150.0 & 20.0 \\
9 & 3 & 0.5 & 150.0 & 20.0 \\
8 & 16 & 8.0 & 200.0 & 30.0 \\
7 & 14 & 1.0 & 200.0 & 30.0 \\
6 & 1 & 8.0 & 100.0 & 30.0 \\
5 & 18 & 1.0 & 100.0 & 30.0 \\
4 & 7 & 8.0 & 200.0 & 10.0 \\
3 & 6 & 1.0 & 200.0 & 10.0 \\
2 & 5 & 8.0 & 100.0 & 10.0 \\
1 & 13 & 1.0 & 100.0 & 10.0 \\
\hline
\end{tabular}

\subsection{Subcritical Water Extraction of Polyphenolics}

Polyphenolic compounds from the apple pomace were extracted under subcritical water mediated hydrolysis conditions according to extraction programme in table 1, using the Parr instrument model (5521), a stainless-steel reactor vessel $(300 \mathrm{~mL})$ of diameter $(2.5 \mathrm{in})$ with heating jacket and a magnetic stirring at 1240 $\mathrm{rpm}$ and integrated cooling system. A back pressure regulatory valve was employed to control internal pressure of vessel. Nitrogen gas was used to purge the reactor and to pressurize the reaction vessel to 50 bar. Crude extracts after subcritical water extraction were collected from the reaction vessel and centrifuged using Beckman J2-20 centrifuge. Supernatants were collected and analysed for phenolic acids and flavonoids and other degradation products.

\subsection{Separation, Identification and Quantification of Polyphenolic Compounds by High Performance Liquid Chromatography (HPLC)}

Reverse phase high performance liquid chromatographic (HPLC) procedure previously described by (Schieber et al., 2001) was used to characterise and quantify the phenolic compounds within the subcritical water extracts. The polyphenolics were resolved based on their respective affinities between the mobile and the stationary phase. The separation of phenolic compounds in extracts were performed using the Agilent 1100 series HPLC system coupled with a DAD-UV detector (Agilent Technologies- Germany), supplied with a solution Chemstation software for both online and offline analysis. A Prodigy 5 $\mu \mathrm{m}$ ODS3 100A, C18 (250 x $4.6 \mathrm{~mm}$ I.D) column from Phenomenex (Torrance, CA, USA) was the stationary phase with a guard column operated at $40^{\circ} \mathrm{C}$. The mobile phase consisted of $2 \%(\mathrm{v} / \mathrm{v})$ of the glacial acetic acid in water as eluent A. Eluent B was made with $0.5 \%$ of acetic acid in 50:50 (v/v) of water and acetonitrile. Eluent $\mathrm{C}$ was $(100 \%)$ acetonitrile. The gradient solvent systems programmed for the separation with a flow rate of $1 \mathrm{ml} / \mathrm{min}$ were as follows: beginning with $10 \%$ of $\mathrm{B}$ and increasing the gradient to 55\% B in 50 minutes. Further increased from 55\% B to $100 \% \mathrm{~B}$ was done in 10 minutes and finally decreased from $100 \%$ B to initial $10 \%$ B in 5 minutes. Eluent $\mathrm{C}$ was used in reconditioning the column under isocratic flow by pumping $100 \% \mathrm{C}$ for 10 minutes, and $10 \% \mathrm{~B}$ also for 10 minutes. Volume of all samples injected at a time was $10 \mu 1$ and phenolic compounds were monitored at $280 \mathrm{~nm}$ (flavanols), $320 \mathrm{~nm}$ (hydrocinnamic acid) and 370nm (flavonols). Retention times and spectra data were collected and identifications of the phenolic compounds were done using their respective retention times and spectra data of respective standards. Quantification of the phenolic compounds were done making use of their chromatographic peak areas at maximum absorbance. 


\subsubsection{Preparation of Polyphenolic Standards}

A standard of chlorogenic acid at concentration of $1 \mathrm{mg} / \mathrm{ml}$ was prepared by weighing $0.05 \mathrm{~g}$ of the solid into a $50 \mathrm{ml}$ volumetric flask and making it up to the mark with HPLC water. $5 \mathrm{ml}$ of the $1 \mathrm{mg} / \mathrm{ml}$ of the stock solution was pipetted into a $50 \mathrm{ml}$ volumetric flask and adding HPLC grade water to the mark to yield a solution of concentration $0.1 \mathrm{mg} / \mathrm{ml}$. The solution was transferred into a $50 \mathrm{ml}$ tube covered with aluminium foil to prevent oxidation from light. $10,100,200,300,500 \mu 1$ of the $0.1 \mathrm{mg} / \mathrm{ml}$ of the chlorogenic acid solution were pipetted into separate HPLC vials and adjusting total volume to $1 \mathrm{ml}$ using HPLC water with $1000 \mu 1$ micropipettes. The solutions were thoroughly mixed to give final concentrations of $1,10,20,30$ and $50 \mu \mathrm{g} / \mathrm{ml}$. $1 \mathrm{ml}$ of the $0.1 \mathrm{mg} / \mathrm{ml}$ $(100 \mu \mathrm{g} / \mathrm{ml})$ was also pipetted into the vial to obtain six different concentrations of samples for the calibration curve. The autosampler of the HPLC was loaded with the standard and were analysed by the method described above. Other phenolic standards were prepared similarly to the chlorogenic acid. Calibration curves were obtained by plotting areas under peaks against concentrations.

2.5.2 Typical Calculation of Concentration of Chlorogenic Acid

The calibration curve for standard chlorogenic acid is shown in Figure 2 below;

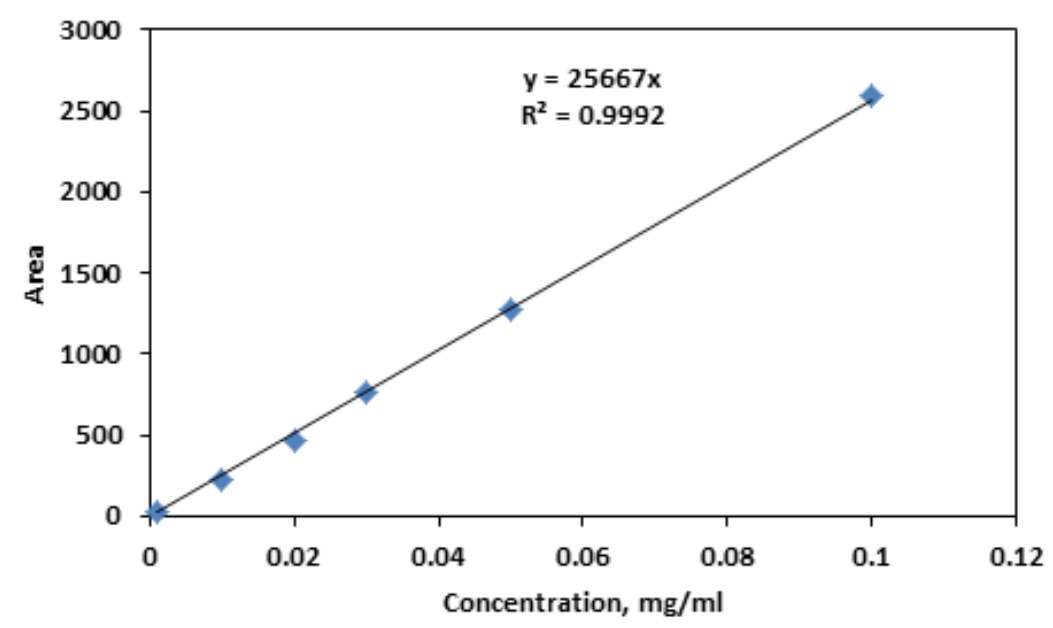

Figure 2. Calibration curve of standard chlorogenic acid

The regression equation for standard chromogenic acid is

$$
y=26612 x
$$

Where $y$ represent peak area, and $x$ is concentration of standard.

$$
\text { Amount of sample (interpolated })=\frac{y}{26612}
$$

The purity of the standard used was taken into consideration and corrected. Purity of Chlorogenic acid used $\geq 95 \%$, therefore the multiplier was;

$$
M=\frac{1}{0.95}=1.0526
$$

And amount of Chlorogenic acid in sample $=\left[\left(\frac{y}{26612}\right) \times 1.0526\right] \mathrm{mg} / \mathrm{ml}$

Conversion of $\mathrm{mg} / \mathrm{ml}$ to $\mathrm{mg} / \mathrm{g} D W$ of apple pomace used was

$$
\text { Amount }\left(\frac{m g}{g} D W\right)=\frac{\left(\text { Amount }\left(\frac{m g}{m l}\right) \times(\text { Volume of extract }, m l)\right.}{\text { Dry weight of apple pomace used, } g}
$$

Similar procedure was used to construct calibration curves for other phenolic standards and their concentrations derived from the graphs. 


\section{Results and Discussion}

The dry matter content of the homogenised apple pomace was $26.2 \pm 0.1 \mathrm{~g} / 100 \mathrm{~g}$ fresh weight. Dry matter content of apple pomace reported in the literature was $26.4 \mathrm{~g} / 100 \mathrm{~g}$ fresh weight (Vasil'ev et al., 1976).

\subsection{Identification of Polyphenolic Compounds under Subcritical Water Extracts}

The extracts from the various design parameter combinations from the subcritical water extraction were analysed using HPLC-DAD. The main phenolic compounds identified were, chlorogenic acid, phloridzin, quercetin-3galactoside, quercetin-3-glucoside, procyanidins B2., and phloretin glycosides. Figures 3- 5 represent chromatograms at temperatures, $100^{\circ} \mathrm{C}, 150^{\circ} \mathrm{C}$ and $200^{\circ} \mathrm{C}$. Table 2 show the retention times of standard polyphenolic compounds.

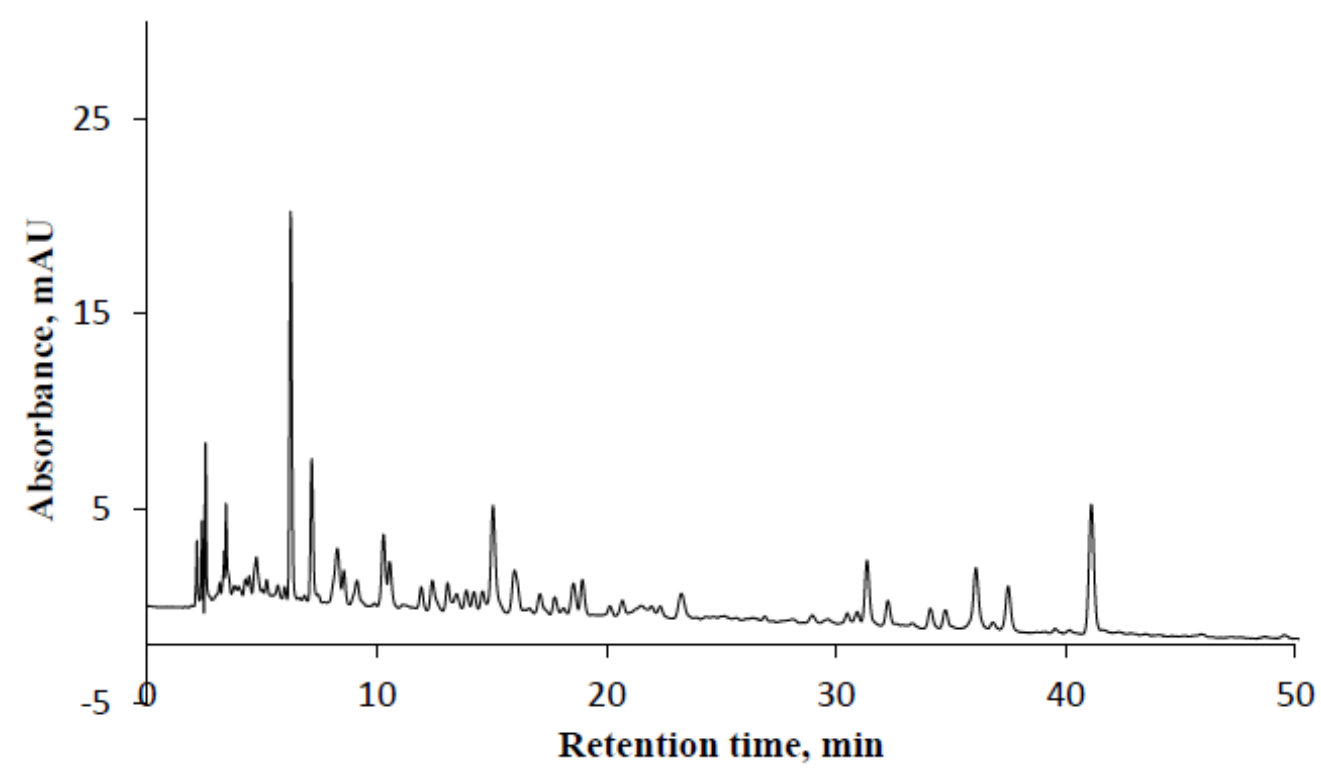

Figure 3. Chromatogram of subcritical water extract of wet cider apple pomace at $100^{\circ} \mathrm{C}$

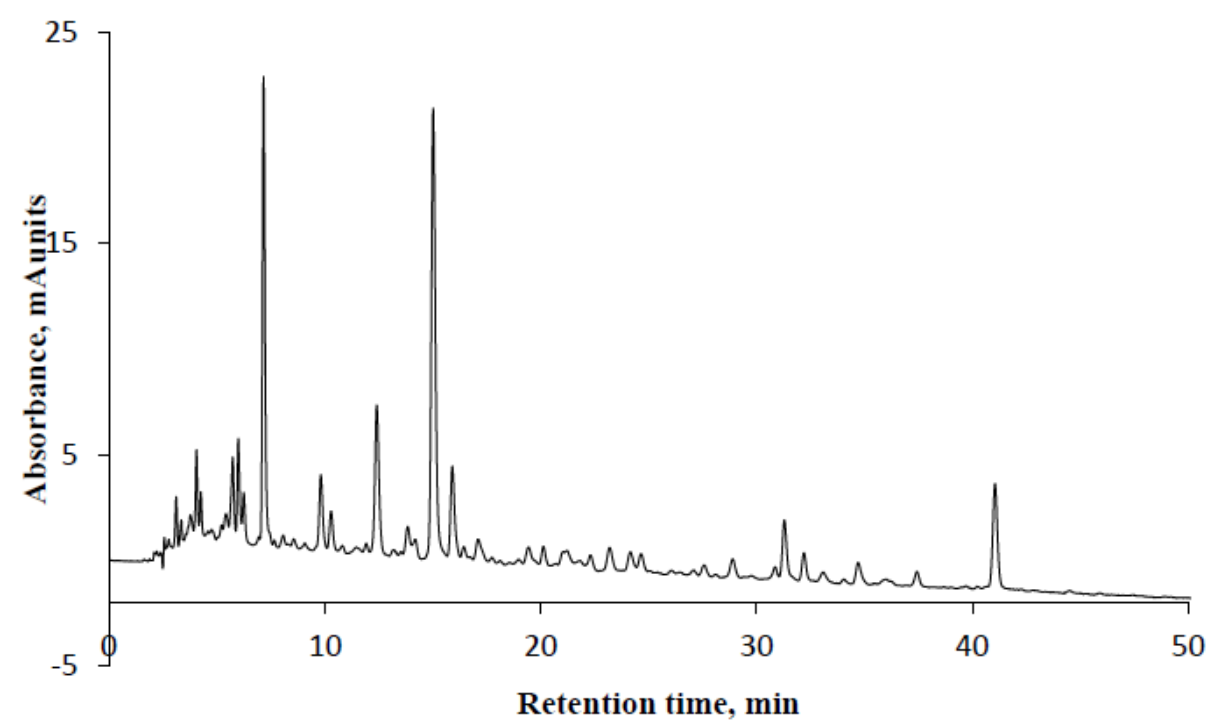

Figure 4. Chromatogram of subcritical water extract of wet cider apple pomace at $150^{\circ} \mathrm{C}$ 


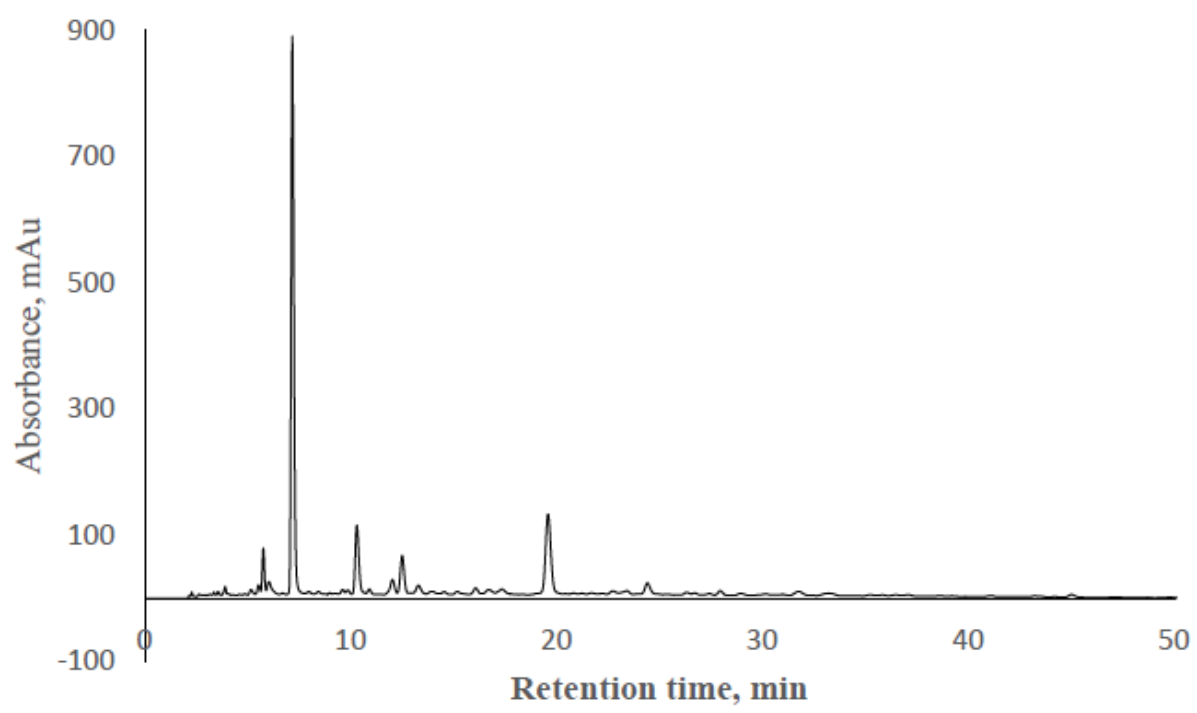

Figure 5. Chromatogram of subcritical water extract of wet cider apple pomace at $200^{\circ} \mathrm{C}$

Table 2. Retention time of standard Phenolic compounds

\begin{tabular}{|c|c|}
\hline Phenolic standard & Retention time (min) \\
\hline Catechin & $13.03 \pm 0.01$ \\
\hline Chlorogenic acid & $15.17 \pm 0.05$ \\
\hline Procyanidin B2 & $16.13 \pm 0.07$ \\
\hline Caffeic acid & $17.5 \pm 0.08$ \\
\hline Epicatechin & $18.6 \pm 0.07$ \\
\hline P-Coumaric acid & $25.3 \pm 0.08$ \\
\hline Ferulic acid & $29.3 \pm 0.20$ \\
\hline Quercetin-3-galactoside & $31.47 \pm 0.11$ \\
\hline Quercetin -3-glucoside & $32.4 \pm 0.01$ \\
\hline Phloridzin & $41.5 \pm 0.23$ \\
\hline Phloretin & $50.32 \pm 0.12$ \\
\hline 5-HMF & $7.3 \pm 0.05$ \\
\hline Furfural & $10.4 \pm 0.06$ \\
\hline Protocatechuic aldehyde & $12.4 \pm 0.06$ \\
\hline
\end{tabular}

Monomeric procyanidins like catechin and epicatechin were barely detected and the reason could be that the UV-DAD was not very good enough for their detection. Protocatechuic aldehyde was detected from $100^{\circ} \mathrm{C}, 150^{\circ} \mathrm{C}$ and $200^{\circ} \mathrm{C}$. The HPLC - DAD characterisation of the polyphenolic compounds of subcritical conditions at $100^{\circ} \mathrm{C}$ reveals among others similar compounds under the aqueous acetone extraction (Ibrahim et al., 2019). These polyphenolic compounds with exception of protocatechuic aldehyde were the main polyphenolic compounds recovered from apple pomace using pressurised ethanol/water as solvents. (Wijngaard \& Brunton, 2009). Phenolic compounds like anthocyanidins were not detected although the apple pomace sample used was a blend of varieties of cider apples including the red ones which were thought to contain high levels of the flavonoid. Anthocyanidins are highly unstable and may even oxidize before the start of the analysis (Delgado-Vargas et al., 2000). However, there were other peaks typically of phenolic nature by their UV- spectra but standards were not available to identify them. Other compounds like 5-hydroxymethylfurral (5-HMF), furfural and Protocatechuic aldehyde are not usually reported in solvent extracts.

\subsection{Determination of Concentration of Phenolic Compounds}

The concentration of phenolic compounds identified were derived from the calibration curves of their pure standards and were recorded as mean values \pm standard error and expressed in $\mathrm{mg} / \mathrm{kg}$ of dry weight of apple pomace as shown in Table 3 and Table 4. 
Table 3. Mean concentration of Chlorogenic acid, Phloridzin, Quercetin-3-galactoside; Quercetin-3-glucoside $(\mathrm{mg} / \mathrm{kg})$ dry weight under subcritical water extraction of wet apple pomace

\begin{tabular}{llllll}
\hline Std Order & Sample & CGA & PHL & Q-3-gal & Q-3-glu \\
\hline 6 & $8-100-30$ & $35.05 \pm 6.3$ & $38.74 \pm 3.6$ & $16.54 \pm 2.5$ & $10.84 \pm 1.9$ \\
11 & $4.5-66-20$ & $6.91 \pm 0.0$ & $50.24 \pm 5.0$ & $22.36 \pm 6.9$ & ND \\
9 & $0.5-150-20$ & ND & ND & ND & ND \\
18 & $4.5-150-20$ & $60.37 \pm 1.8$ & $57.61 \pm 2.4$ & $12.712 \pm 0.7$ & $21.43 \pm 0.2$ \\
2 & $8-100-10$ & $24.67 \pm 1.3$ & $31.43 \pm 1.32$ & $16.66 \pm 0.5$ & $12.91 \pm 0.4$ \\
3 & $1-200-10$ & ND & ND & ND & ND \\
4 & $8-200-10$ & ND & ND & ND & ND \\
12 & $4.5-234-20$ & ND & ND & ND & ND \\
15 & $4.5-150-20$ & $60.14 \pm 0.4$ & $48.30 \pm 7.0$ & $14.45 \pm 0.5$ & $18.68 \pm$ \\
20 & $4.5-150-20$ & $59.18 \pm 2.8$ & $43.48 \pm 1.7$ & $11.29 \pm 0.2$ & $19.46 \pm$ \\
14 & $4.5-150-37$ & $54.90 \pm 1.7$ & $44.80 \pm 2.3$ & $10.59 \pm 2.4$ & $20.88 \pm 2.6$ \\
13 & $4.5-150-3$ & $59.4 \pm 2.4$ & $50.49 \pm 2.8$ & $25.07 \pm 1.1$ & $22.97 \pm 1.7$ \\
1 & $1-100-10$ & $58.39 \pm 0.6$ & $60.73 \pm$ & $76.16 \pm 0.7$ & ND \\
7 & $1-200-30$ & ND & ND & ND & ND \\
17 & $4.5-150-20$ & $60.56 \pm 1.5$ & $45.29 \pm 2.6$ & $15.30 \pm 0.9$ & $18.32 \pm 4.9$ \\
8 & $8-200-30$ & ND & ND & ND & ND \\
16 & $4.5-150-20$ & $34.49 \pm 1.2$ & $22.37 \pm 4.3$ & $25.33 \pm 1.67$ & $28.24 \pm 4.7$ \\
5 & $1-100-30$ & $122.21 \pm 1.9$ & $250.20 \pm 22.2$ & $97.00 \pm 0.7$ & ND \\
10 & $9.5-150-20$ & $40.21 \pm 0.4$ & $31.53 \pm 1.2$ & $5.83 \pm 0.7$ & $8.87 \pm 2.9$ \\
19 & $4.5-150-20$ & $78.33 \pm 2.7$ & $89.21 \pm 1.02$ & $19.24 \pm 1.4$ & $23.59 \pm 4.9$ \\
\hline
\end{tabular}

Note: Sample 8-100-30 reads; $8 \%$ solid/solvent @ $100^{\circ} \mathrm{C}$ for 30 minutes;

CGA- Chlorogenic acid; PHL- Phloridzin; Q-3-gal- Quercetin-3-galactoside; Q-3-glu-Quercetin-3-glucoside, ND -not detected.

Table 4. Mean concentration of Procyanidin B2, Protocatechuic aldehyde, 5-HMF and Furfural (mg/kg) dry weight under subcritical water extract of wet apple pomace

\begin{tabular}{llllll}
\hline Std order & Sample & Pr-B2 & PCA & Furfural & 5-HMF \\
\hline 6 & $8-100-30$ & $57.67 \pm 5$ & ND & $16.09 \pm 1.7$ & $4.19 \pm 0$ \\
11 & $4.5-66-20$ & ND & ND & ND & ND \\
9 & $0.5-150-20$ & ND & ND & ND & $150.89 \pm 8.1$ \\
18 & $4.5-150-20$ & ND & $39.6 \pm 0.3$ & $628.75 \pm 71$ & $194.05 \pm 33.0$ \\
2 & $8-100-10$ & $48.55 \pm 0.1$ & ND & $4.40 \pm 0.23$ & $2.02 \pm 1.4$ \\
3 & $1-200-10$ & ND & $674.2 \pm 0.1$ & $17980.39 \pm 406$ & $3754.93 \pm 67.7$ \\
4 & $8-200-10$ & ND & $337.8 \pm 0.5$ & $6653.63 \pm 103$ & $633.27 \pm 2.7$ \\
12 & $4.5-234-20$ & ND & $1133.2 \pm 0.6$ & $15787.68 \pm 265$ & $1543.86 \pm 13.5$ \\
15 & $4.5-150-20$ & ND & $40.5 \pm 0.2$ & $590.89 \pm 42.5$ & $168.32 \pm 6.1$ \\
20 & $4.5-150-20$ & ND & $38.6 \pm 1.4$ & $631.12 \pm 14.5$ & $175.12 \pm 6.0$ \\
14 & $4.5-150-37$ & ND & $62.2 \pm 0.0$ & $1042.49 \pm 74.1$ & $342.83 \pm 1.8$ \\
13 & $4.5-150-3$ & ND & $18.4 \pm 0.1$ & $177.61 \pm 20.3$ & $33.36 \pm 1.8$ \\
1 & $1-100-10$ & ND & ND & $46.27 \pm 0.4$ & $6.48 \pm 0.2$ \\
7 & $1-200-30$ & ND & $966.4 \pm 0.1$ & $40330.39 \pm 786$ & $5767.29 \pm 170.5$ \\
17 & $4.5-150-20$ & ND & $39.7 \pm 0.1$ & $588.45 \pm 1.57$ & $162.24 \pm 3.1$ \\
8 & $8-200-30$ & ND & $357.4 \pm 23.9$ & $9038.32 \pm 158.6$ & $795.93 \pm 1.8$ \\
16 & $4.5-150-20$ & ND & $41.8 \pm 0.1$ & $753.07 \pm 148$ & $201.94 \pm 46.3$ \\
5 & $1-100-30$ & ND & ND & $97.78 \pm 9.3$ & $4.34 \pm 0.5$ \\
10 & $9-150-20$ & ND & $44.5 \pm 1.1$ & $652.88 \pm 1.03$ & $212.95 \pm 5.0$ \\
19 & $4.5-150-20$ & ND & $41.6 \pm 0.0$ & $594.97 \pm 11.9$ & $185.97 \pm 7.0$ \\
\hline
\end{tabular}

Note: $1-100-30$ reads $1 \%$ solid-to-solvent ratio at $100^{\circ} \mathrm{C}$ for 30 minutes residence time; Pr-B2= Procyanidin B2; $\mathrm{PCA}=$ Protocatechuic aldehyde $\mathrm{ND}=$ not detected; 


\subsection{Model Analysis of Chlorogenic Acid and other Flavonoids in the Subcritical Water Extracts}

Chlorogenic acid, phloridzin, quercetin-3-galactoside, quercetin-3-glucoside, procyanidin B2 and degradation compounds (protocatechuic aldehyde, 5-HMF and furfural) were evaluated for effects of solid-to solvent ratio, temperature and residence time on overall recovery of the dependent variables using concentrations of each compound in table 3 and table 4. Individual concentrations were each entered into design expert 7.0 software for model selection. The model selection criteria were that, selected model should be significant and exhibit an insignificant lack of fit, in addition to satisfactory levels of adequacy. ANOVA results at $95 \%$ confidence interval for all proposed models were significant $(p<0.05)$ with satisfactory level of adequacies $\left(R^{2}>0.9\right)$ and predicted $\mathrm{R}^{2}$ largely agreed with adjusted $\mathrm{R}^{2}$. Coefficient of variations and variance of inflation factors were at acceptable levels. Transformed reduced quadratic models were appropriate and revealed the effect of each dependent variable on extraction conditions. The summary on the levels of significance of design factors and their interaction are shown in Table 5.

Table 5. Summary of the levels of significance of design factors and interaction terms under subcritical water extraction

\begin{tabular}{llllllllll}
\hline Response & \multicolumn{10}{l}{ Significant level (p $<0.05)$} \\
\cline { 2 - 8 } & A & B & C & AB & AC & BC & A $^{2}$ & B $^{2}$ & C $^{2}$ \\
\hline CGA & $\checkmark$ & $\checkmark$ & & $\checkmark$ & & & & $\checkmark$ & \\
PHL & $\checkmark$ & $\checkmark$ & & $\checkmark$ & & & $\checkmark$ & $\checkmark$ & \\
Q-3-gal. & $\checkmark$ & $\checkmark$ & & $\checkmark$ & & & $\checkmark$ & & \\
Q-3-glu. & $\checkmark$ & $\checkmark$ & & $\checkmark$ & & & $\checkmark$ & & \\
Pr-B2 & $\checkmark$ & $\checkmark$ & & $\checkmark$ & & & $\checkmark$ & & \\
PCA & $\checkmark$ & $\checkmark$ & $\checkmark$ & & $\checkmark$ & $\checkmark$ & $\checkmark$ & & \\
5-HMF & $\checkmark$ & $\checkmark$ & $\checkmark$ & $\checkmark$ & & $\checkmark$ & $\checkmark$ & & \\
Furfural & $\checkmark$ & $\checkmark$ & $\checkmark$ & $\checkmark$ & & $\checkmark$ & $\checkmark$ & & \\
\hline
\end{tabular}

Note: CGA-chlorogenic acid; PHL-phloridzin; Q-gal- quercetin-3-galactoside; Q-glu- quercetin-3- glucoside; Pr-B2-procyanidin B2; A-solid-to-solvent ratio; B-temperature, and C-residence time in reactor, $\checkmark$ - significant.

Solid-to-solvent ratio (A), temperature (B) and their interaction (AB) had significant effects on the yield of all responses. Effect of residence time was not significant on recovery of the phenolic compounds. This observation was consistent with earlier published report of flavonoids extraction under subcritical water extraction (Plaza et al., 2013). Residence time influenced the yield of protocatechuic aldehyde, 5-HMF and furfural as well it's (residence time) interaction with temperature. Higher temperatures and extended time favoured the yield of the decomposition or degradation products.

\subsubsection{Effects of Extraction Conditions on Recovery of Chlorogenic Acid}

Yield of chlorogenic acid was significantly affected by loading ratio (solid/solvent) and temperature as well as their interaction $(\mathrm{P}<0.05)$. Only temperature showed significant effect in the quadratic term $(\mathrm{p}<0.05)$. Residence time had no significant influence on the recovery of chlorogenic acid $(p>0.05)$. Maximum concentration of chlorogenic acid $\left(122.2 \mathrm{mg} / \mathrm{kg}\right.$ ) was extracted around $100^{\circ} \mathrm{C}$. Chlorogenic acid had been reported to degrade at temperature $112^{\circ} \mathrm{C}$ during pressurised liquid extraction of antioxidants from apple pomace using a mixture of ethanol and water as solvent (Wijngaard \& Brunton, 2009). A phenolic compound which share similar spectra characteristics with chlorogenic acid was observed at temperature at $150^{\circ} \mathrm{C}$ with retention time 16.06 minutes. Chlorogenic acid which is an ester of caffeic acid and quinic acid, has several isomers and classified based on the number and position of the acyl groups attached to them. The isomers include; 5-O- caffeeoylquinic acid (common one), 4-O- caffeeoylquinic acid and others with two caffeic acid molecules referred to as iso chlorogenic acid comprising 3,4, dicaffeeoyliquinic acid and 3,5, dicaffeeoyliquinic acid (Clifford, 2000). On the other hand, Winjgaard and Brunton reported, an increased in chlorogenic acid concentration at temperatures higher than $160^{\circ} \mathrm{C}$ and attributed the release from a possible noncovalent relationship of chlorogenic acid with melanoidins. Similarly Plaza and co-workers predicted maximum concentration of 5-caffeoquinic acid (chlorogenic acid) from apple pomace to elute between $175-200^{\circ} \mathrm{C}$ (Plaza et al., 2013). Chlorogenic acid or any of its isomers were not detected at temperature $200^{\circ} \mathrm{C}$ in this investigation. The transformed polynomial model for chlorogenic acid as in (1);

$$
\sqrt{\text { Chlorogenic acid }}=-14.66360-1.11557 A+0.38727 B+0.19207 C+5.57786 \times 10^{-3} A B
$$




$$
-1.09174 \times 10^{-3} B C-1.55493 \times 10^{-3} B^{2}
$$

was used to navigate the design space and no prediction of any higher concentrations for chlorogenic acid at higher temperatures was observed. Response surface plots for recovery of chlorogenic acid showing the effects of solid/solvent ratio, temperature at a fixed residence time of 20 minutes is shown in Figure 6.

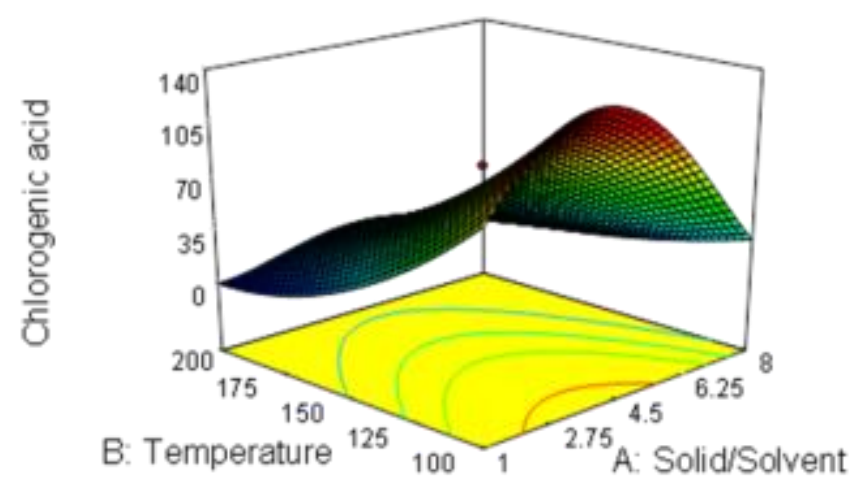

Figure 6. Response surface plot for the effects of temperature $\left({ }^{\circ} \mathrm{C}\right)$ and solid/solvent ratio \% (w/v) on the concentration of Chlorogenic acid $(\mathrm{mg} / \mathrm{kg})$ der weight under subcritical water extraction of apple pomace for a residence time 20 minutes

\subsubsection{Effects of Extraction Conditions on Recovery of Phloridzin}

Phloridzin is a major phenolic glycoside found in apple trees and has a characteristic bitter taste that contribute to the original flavour of cider (Whiting \& Coggins, 1975). Maximum concentration of the dihydrochalcone glycosides in extracts was $250.2 \mathrm{mg} / \mathrm{kg}$ at $100^{\circ} \mathrm{C}$, a condition consistent with similar extractions using ethanol/water as solvents for extraction (Wijngaard \& Brunton, 2009). However, it began to degrade at around $120^{\circ} \mathrm{C}$. Phloridzin was not detected at temperature $200^{\circ} \mathrm{C}$. The transformed polynomial model is shown in equation (2).

$\sqrt{\text { Phloridzin }}=+8.95591-3.88579 A+0.22440 B+0.014146 A B+0.11739 A^{2}-1.32240 \times 10^{-3} B^{2}$

The response surface plots show highest amount of phloridzin at $100^{\circ} \mathrm{C}$ and stay relatively constant until around $120^{\circ} \mathrm{C}$ and gradually decreases to zero at $200^{\circ} \mathrm{C}$. The model could be used to navigate the design space. Similar to Chlorogenic acid, Plaza et al., 2013 reported a deviation of response surface plots for phloridzin under pressurised hot water extraction of apple peels (Plaza et al., 2013), predicting higher yield at the highest temperatures $\left(170-200^{\circ} \mathrm{C}\right)$. Response surface plots showing the effects of temperature, solid- to- solvent ratio at fixed residence time of 20 minutes on the yield of phloridzin is shown in Figure 7.

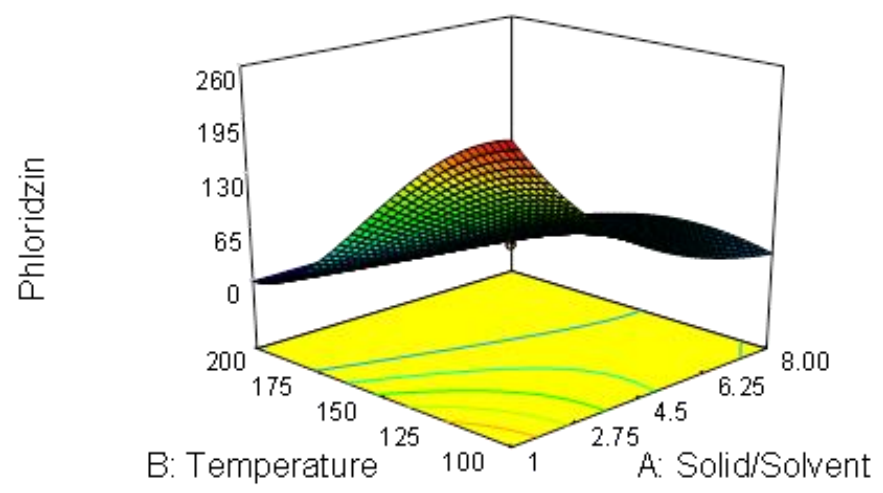

Figure 7. Response surface plot for the effects of temperature $\left({ }^{\circ} \mathrm{C}\right)$ and solid/solvent ratio $\%(\mathrm{w} / \mathrm{v})$ on the amount of Phloridzin $(\mathrm{mg} / \mathrm{kg})$ dry weight under subcritical water extraction of apple pomace for residence time of 20 minutes 


\subsubsection{Effects of Extraction Conditions on Recovery Procyanidin B2}

Structural and molecular weight variation within proanthocyanidins makes their evaluation very challenging. Moreover, their complexation with other non-soluble polymers, under estimate their quantification due to incomplete extraction (Pérez-Jiménez et al., 2009). About 50-93\% of apple procyanidins may be retained within cell wall material during processing of apple juice (Le Bourvellec \& Renard, 2012). Concentrations of procyanidin B2 under subcritical water extraction varied from $0.00-57.67 \pm 5.30 \mathrm{mg} / \mathrm{kg} \mathrm{dw}$ and the yield of procyanidin B2 was both solid-to solvent ratio and temperature dependent as well as their interaction. Residence time had no influence on overall amount of procyanidin B2 under the subcritical water extraction within selected range. Procyanidin $\mathrm{B} 2$ was not detected at $150^{\circ} \mathrm{C}$ and beyond suggesting that the amount originally accumulated at $100^{\circ} \mathrm{C}$ would have been degrading. Therefore, it was not advisable to pursue predictive modelling based on the selected range. Although the design expert suggested predictive model and this could not be relied upon due to limited data because contour plots may be misleading. Optimal temperature conditions of $80-140^{\circ} \mathrm{C}$ were reported for extracting procyanidins from grape pomace using ethanol /water mixture as solvents (Monrad et al., 2010).

\subsubsection{Effects of Extraction Conditions on Recovery of Quercetin Glycosides}

The two quercetin glycosides have differed in the way they responded to changes in temperature and solid- tosolvent ratio. Quercetin-3-galactoside was influenced slightly by temperature whereas quercetin-3-glucoside was controlled by solid-to-solvent ratio both in the quadratic terms. The interaction between solid-to solvent ratio and temperature was positive for quercetin-3-galactoside and negative for quercetin-3-gluctoside. The difference in the behaviour could be attributed to the structural configuration of galactose and glucose moieties attached to the quercetin aglycone. Although glucose and galactose can both occur in either open or cyclic structures, the five (5) hydroxyl groups in glucose can be arranged in a specific way on the six-carbon backbone whereas galactose has a carbonyl towards the end of chain. These configurations contribute to the different boiling points of the sugars despite identical molecular weights as they are isomers $(180.156 \mathrm{~g} / \mathrm{mol}$ for glucose and $180.16 \mathrm{~g} / \mathrm{mol}$ for galactose). Boiling points of glucose and galactose are $146-150^{\circ} \mathrm{C}$ and $167^{\circ} \mathrm{C}$ respectively. Boiling points are reflection of the strength of the forces between molecules and indication of ease of separation of components which are bound together. Both quercetin glycosides have positive linear temperature coefficients which suggested their concentrations increase in extracts initially when temperature was raised up to $100^{\circ} \mathrm{C}$. However further increase in temperature negatively affected the yields of the glycosides shown in the polynomial model equations (3) and (4).

$$
\begin{aligned}
\text { Quercetin }-3-\text { galactoside }= & +95.97583-31.76127 A+0.45032 B+0.085086 A B+ \\
& 1.63824 A^{2}-4.32336 \times 10^{-3} B^{2}
\end{aligned}
$$

$$
\text { quercetin }-3-\text { glucoside }=-15.02656+16.48077 A+0.016964 B-0.016964 A B-1.45421 A^{2}
$$

The coefficients values of interaction between solid-to solvent and temperature for both glycosides indicated that, it was not advantageous to the yield of quercetin-3-galactoside when both factors are increased simultaneously, whereas it positively influences the amount of the quercetin-3-glucoside as shown in the response surface plots in Figures 8 and 9.

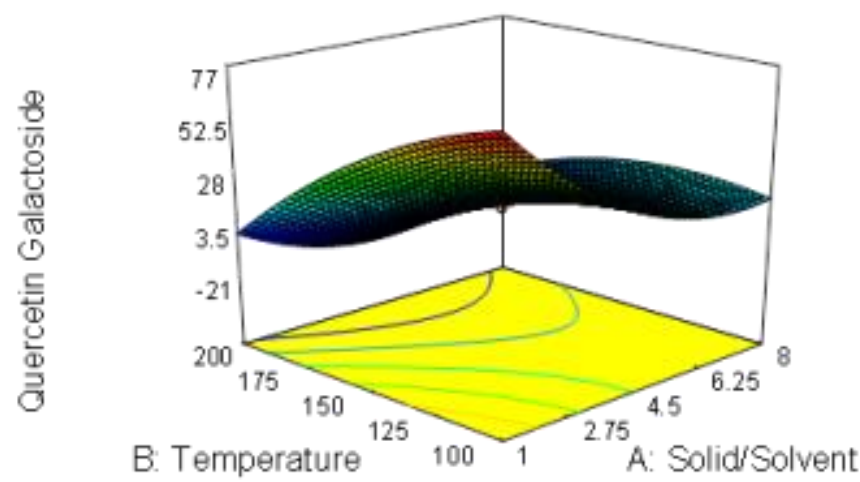

Figure 8. Response surface plot for the effects of temperature $\left({ }^{\circ} \mathrm{C}\right)$ and solid/solvent ratio $\%(\mathrm{w} / \mathrm{v})$ on the amount of Quercetin-3- galactoside ( $\mathrm{mg} / \mathrm{kg}$ ) dry weight for 20 minutes residence time under subcritical water extraction of apple pomace 


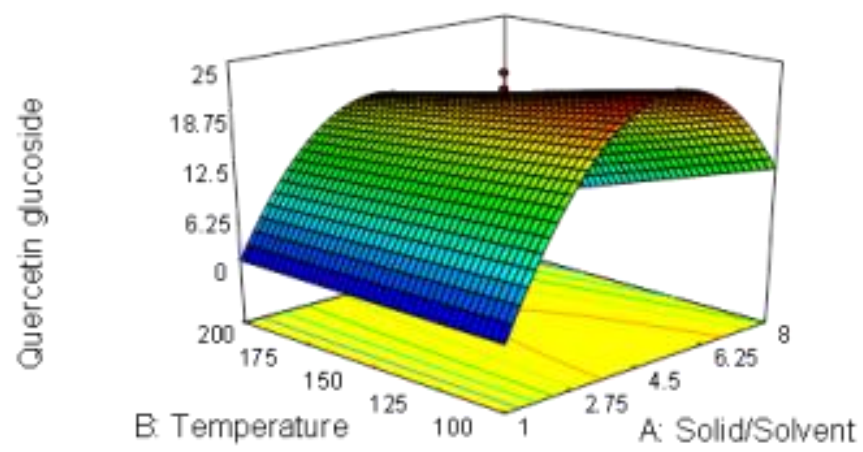

Figure 9. Response surface plot for the effects of temperature $\left({ }^{\circ} \mathrm{C}\right)$ and solid/solvent ratio $\%(\mathrm{w} / \mathrm{v})$ on the amount of Quercetin-3- glucoside ( $\mathrm{mg} / \mathrm{kg}$ ) dry weight for 20 minutes residence time under subcritical water extraction of apple pomace

\subsubsection{Effects of Extraction Conditions on Recovery Protocatechuic Aldehyde}

3, 4 - dihydroxybenzaldehyde otherwise known as protocatechuic aldehyde is not found freely in apples. Protocatechuic aldehyde which demonstrates strong effect by suppressing replication of hepatitis B-virus both in vitro and in vivo studies is a stable product of thermal degradation of chlorogenic acid (Moon \& Shibamoto, 2010; Zhou et al., 2007). The phenolic aldehyde was also the main stable compound from caffeic acid degradation under subcritical water conditions within $160-240^{\circ} \mathrm{C}$ (Khuwijitjaru et al., 2014). Water soluble protocatechuic aldehyde in the extracts ranged from $0-966.4 \mathrm{mg} / \mathrm{kg}$ within the limits of design parameters. Protocatechuic aldehyde was not detected at $100^{\circ} \mathrm{C}$ but noticeable at $150^{\circ} \mathrm{C}$, and was stable in the extract even up to $234^{\circ} \mathrm{C}$. Yield of protocatechuic aldehyde increases from $150^{\circ} \mathrm{C}$ to $200^{\circ} \mathrm{C}$ with increasing residence time up to 30 minutes. However, it decreases as solid- to- solvent ratio approaches $8 \%$ meaning decreasing the loading and increasing both temperature and residence time improves the yield of protocatechuic aldehyde as in equation (5).

$$
\begin{gathered}
\sqrt{P C A}=-25.29499-2.30741 A+0.27115 B-0.052261 C-0.014120 A B-0.016414 A C+1.41183 \times \\
10^{-3} B C+0.44974 \times 10^{-3} A^{2}
\end{gathered}
$$

Response surface plots depicting this behaviour of temperature, solid to solvent ratio and residence time are shown Fig 10 below;

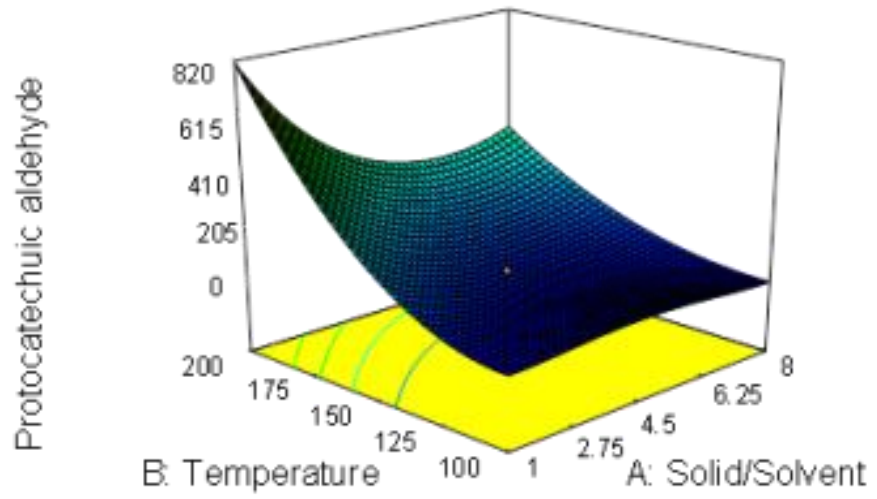

Figure 10. Response surface plot for the effects of temperature $\left({ }^{\circ} \mathrm{C}\right)$ solid/solvent ratio $\%(w / v)$ on theamount of Protocatechuic aldehyde $(\mathrm{mg} / \mathrm{kg}$ ) dry weight for 20 minutes residence time under subcritical water extraction of apple pomace

\subsubsection{Effects of Extraction Conditions for 5-HMF and Furfural}

5-HMF and furfural constitutes furan derivatives and are by-products of hexose and xylose degradation respectively (Ulbricht et al., 1984). The subcritical water extracts of the apple pomace contained varying 
concentration of monomeric sugars which degraded at higher temperatures and extended periods under the batch operations to produce the two maillard agents. 5-HMF and furfural varied significantly with temperature and solid to solvent ratio as shown in the model equations (6) and (7).

$$
\begin{array}{r}
\sqrt{5 H M F}=-57.06203-1.78796 A+0.63427 B-0.26542 C-0.059059 A B-0.037606 A C+4.38730 \times \\
10^{-3} B C+0.92923 A^{2} \\
\sqrt{\text { Furfural }}=-77.74299-22.99902 A+1.22185 B-2.21599 C-0.098922 A B+0.021109 B C+ \\
3.49756 A^{2}
\end{array}
$$

High temperature favoured the formation of the furanic compounds which are also influenced by $\mathrm{pH}$ (Purlis, 2010). Increase in temperature under subcritical conditions decreased the $\mathrm{pH}$ of water which enhances the dehydration reaction to 5-HMF (Aida et al., 2007). 5- $\mathrm{HMF}$ and furfural were not detected at temperatures $66^{\circ} \mathrm{C}$ which is consistent with results reported earlier (Çam \& Aaby, 2010, Schieber et al., 2001). Lower concentrations of $2.02 \mathrm{mg} / \mathrm{kg}$ and $4.4 \mathrm{mg} / \mathrm{kg}$ of $5-\mathrm{HMF}$ and furfural were recorded at $100^{\circ} \mathrm{C}$ respectively. Concentrations of $5767.3 \mathrm{mg} / \mathrm{kg}$ and $40330.4 \mathrm{mg} / \mathrm{kg}$ of $\mathrm{HMF}$ and furfural respectively were achieved at $200^{\circ} \mathrm{C}$ with corresponding increase in browning of extract suggesting caramelisation reactions taking place. The response surface plots showing the effects of solid-to solvent ratio and temperature on maillard agents are shown in Figure 11 and 12.

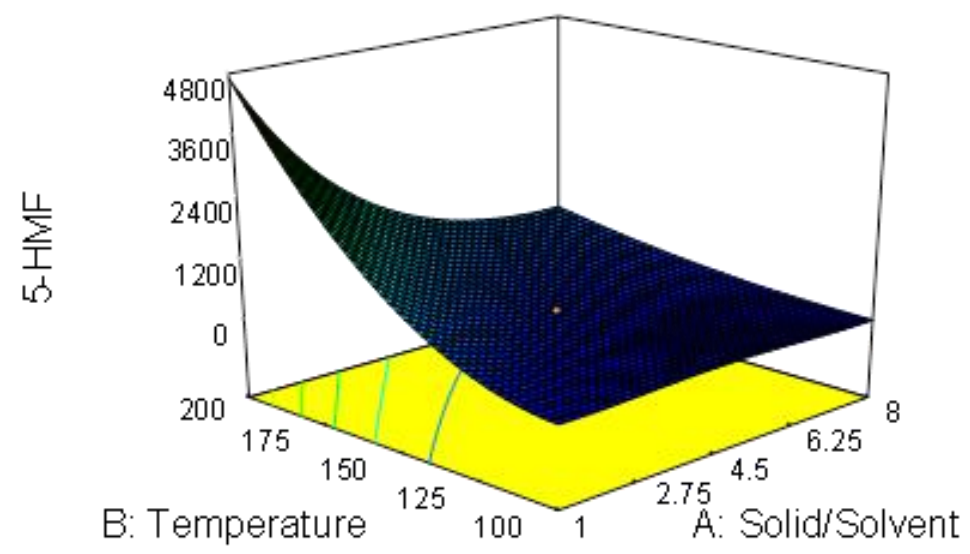

Figure 11. Response surface plot of effects of temperature $\left({ }^{\circ} \mathrm{C}\right)$ and solid-to solvent ratio $\%(\mathrm{w} / \mathrm{v})$ on $5-\mathrm{HMF}$ $(\mathrm{mg} / \mathrm{kg})$ dry weight for 20 minutes residence time under the subcritical water extraction of apple pomace

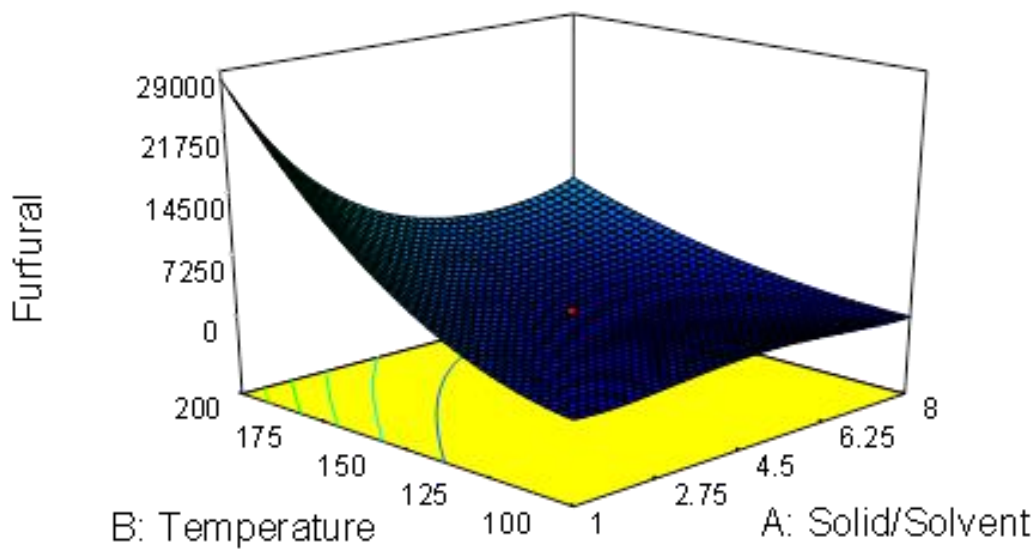

Figure 12. Response surface plot of effects of temperature $\left({ }^{\circ} \mathrm{C}\right)$ and solid-to solvent ratio $\%(\mathrm{w} / \mathrm{v})$ on furfural $(\mathrm{mg} / \mathrm{kg})$ dry weight for 20 minutes extraction time under the subcritical water extraction of apple pomace 


\section{Conclusion}

Recovery of chlorogenic acid and flavonoids were strongly influenced by solid to solvent ratio and temperature under the subcritical water mediated extraction of the cider apple pomace. Residence time during extraction at lower subcritical water temperature had little significance on overall recovery of the polyphenolic compounds. However, its effect at higher temperature was significant and resulted in the formation of degradation products like protocatechuic aldehyde and furan derivatives. Higher yields of chlorogenic acid and the flavonoids were obtained between $100-150^{\circ} \mathrm{C}$ for residence time of 20 minutes. Solid-to solvent ratio and temperature played a significant role in the recovery of the polyphenolic compounds $(\mathrm{p}<0.05)$. The subcritical water condition selectively affected the chemical structure of the phenolic acid and the flavonoids particularly quercetin-3glucoside and quercetin-3- galactoside.

\section{Acknowledgement}

We greatly acknowledge Universal Beverages Limited (UBL), UK for supplying the cider apple pomace sample and Ghana Education Trust Fund (GETFund) for supporting the research financially.

\section{References}

Adom, K. K., \& Liu, R. H. (2002). Antioxidant activity of grains. Journal of Agricultural and Food Chemistry, 50, 6182-6187. https://doi.org/10.1021/jf0205099

Aida, T. M., Sato, Y., Watanabe, M., Tajima, K., Nonaka, T., \& Hattori, H. (2007). Dehydration of -glucose in high temperature water at pressures up to $80 \mathrm{MPa}$. The Journal of Supercritical Fluids, 381-388. https://doi.org/10.1016/j.supflu.2006.07.027

Arai, Y., Sako, T., \& Takebayashi, Y. (2013). Supercritical fluids: molecular interactions, physical properties and new applications. Springer Science \& Business Media.

Brendan, L. (2010). Apples. Washington DC, United State International Trade Commission.

Çam, M., \& Aaby, K. (2010). Optimization of Extraction of Apple Pomace Phenolics with Water by Response Surface Methodology. Journal of Agricultural and Food Chemistry, 58(16), 9103-9111. https://doi.org/10.1021/jf1015494

Cetkovic, G., Canadanović-Brunet, J., Djilas, S., Savatović, S, Mandić, A., \& Tumbas, V. (2008). Assessment of polyphenolic content and in vitro antiradical characteristics of apple pomace. Food Chemistry, 109(2), 340-347. https://doi.org/10.1016/j.foodchem.2007.12.046

Chandrasekara, A., \& Shahidi, F. (2010). Content of insoluble bound phenolics in millets and their contribution to antioxidant capacity. Journal of Agricultural and Food Chemistry, 58, 6706-6714. https://doi.org/10.1021/jf100868b

Clifford, M. N. (2000). Chlorogenic acids and other cinnamates-nature, occurrence, dietary burden, absorption and metabolism. Journal of the Science of Food and Agriculture, 80(7), 1033-1043. https://doi.org/10.1002/(SICI)1097-0010(20000515)80:7<1033::AID-JSFA595>3.0.CO;2-T

D’Archivio, M., Filesi, C., Di Benedetto, R., et al. (2007). Polyphenols, dietary sources and bioavailability. Annali dell'Istituto Superiore Di Sanita, 43, 348-361.

Delgado-Vargas, F., Jimenez, A. R., \& Pardes-Lopez, O. (2000). Natural pigments: carotenoids, anthocyanins and betalainsecharacteristics, biosynthesis, processing and stability. Critical Reviews in Food Science and Nutrition, 40, 173-289. https://doi.org/10.1080/10408690091189257

Diñeiro, G. Y., Valles, B. S., \& Picinelli, L. A. (2009). Phenolic and antioxidant composition of by-products from the cider industry: Apple pomace. Food Chemistry, 117(4), 731-738.

https://doi.org/10.1016/j.foodchem.2009.04.049

FOA (2011). Food and Agricultural Organization of the United Nations. Retrieved from http://faostat.fao.org/site/567/DesktopDefault.aspx?PageID=567 FOASTAT [Accessed 2011]

Foo, L.Y. and Lu, Y. (1999). Isolation and identification of procyanidins in apple pomace. Food Chemistry, 64(4), 511-518. https://doi.org/10.1016/S0308-8146(98)00150-2

Harborne, J., \& Williams, C. (2000). Advances in flavonoid research since 1992. Phytochemistry, 55, 481-504. https://doi.org/10.1016/S0031-9422(00)00235-1

Hollman, P. C., van Trijp, J., Buysman, M. N., van der Gaag, M. S., Mengelers, M. J., de Vries, J. H., \& Katan, M. B. (1997). Relative bioavailability of the various antioxidant flavonoid quercetin from various foods in 
man. FEBS Letters, 418(1-2), 152-156. https://doi.org/10.1016/S0014-5793(97)01367-7

Ibáñez, E., Mendiola, J. A., Rodríguez-Meizoso, Javier, S. F., Guillermo, R., \& Alejandro, C. (2008). Antioxidants in plant foods and microalgae extracted using compressed fluids. Electronic Journal of Environmental, Agricultural and Food Chemistry, 7(8), 3301-3309.

Ibrahim, S., Santos, R., \& Bowra, S. (2019). Optimisation of Organic Solvent Mediated Solubilisation of Apple Pomace Polyphenolic Compounds Using Response Surface Methodologies. International Journal of Chemistry, 11(2), 1-21. https://doi.org/10.5539/ijc.v11n2p1

Ibrahim, S., Santos, R., \& Bowra, S. (2018). Optimization of Subcritical Water Mediated Extraction of Apple Pomace Polyphenolics and their Antioxidant Activity. J Chromatogr Sep Tech, 9, 410. https://doi.org/10.4172/2157-7064.1000410

Johansen, K., (2000). Cider Production in England and France - and Denmark? Danbrew Ltd. A/S. Retrieved from https://www.yumpu.com/en/document/read/10581991/cider-production-in-england-and-france-and-denmark

Joshi, V. K. (1997). Fruit wines, $2^{\text {nd }}$ edition Dr. YS Parmar University of Horticulture and Forestry, Solan, India.

Joshi, V.K., \& Attri, B.L. (1991). Importance and scope of fruit based fermented beverages in India. Beverage and Food World, 17(4), 9-10.

Joshi, V. K., Kaushal, N. K., \& Thakur, N. S. (1996) Apple pomace sauce development, quality of fresh and stored products. Journal of. Food Science and Technology, 33, 414-419.

Joshi, V. K., \& Sandhu, D. K. (1996). Preparation and evaluation of animal feed using solid state fermentation of apple. Bioresource Technology, 56, 251-255. https://doi.org/10.1016/0960-8524(96)00040-5

Kaushal, N., Joshi, V., \& Sharma, R. (2002). Effect of stage of apple pomace collection and the treatment on the physical-chemical and sensory qualities of pomace papad (fruit cloth). Journal of Food Science and Technology, 39, 388-393.

Kennedy, M., List, D., Lu, Y., Newman, R. H., Sims, I. M, Bain, P. J. S., Hamilton, B., \& Fenton, G. (1999). Apple pomace and products derived from apple pomace: Uses, composition and analysis. Berlin: Heidelberg: Springer. https://doi.org/10.1007/978-3-662-03887-1_4

Khuwijitjaru, P., Suaylam, B., \& Adachi, S. (2014). Degradation of Caffeic Acid in Subcritical Water and Online HPLC-DPPH Assay of Degradation Products. Journal of Agricultural and Food Chemistry, 62(8), 1945-1949. https://doi.org/10.1021/jf404850a

Kim, K.-H., Tsao, R., Yang, R., \& Cui, S. W. (2006). Phenolic acid profiles and antioxidant activities of wheat bran Extracts and the effect of hydrolysis conditions. Food Chemistry, 95(3), 466-473. https://doi.org/10.1016/j.foodchem.2005.01.032

Le Bourvellec, C., \& Renard, C. (2012) Interactions between polyphenols and macromolecules: quantification methods and mechanisms. Critical Reviews in Food Science and Nutrition, 52(3), 213-248. https://doi.org/10.1080/10408398.2010.499808

Liu, R. H. (2003). Health benefits of fruits and vegetables are from additive and synergistic combination of phytochemicals. The American journal of clinical nutrition, 78(3), 517-520. https://doi.org/10.1093/ajcn/78.3.517S

Lu, Y., \& Foo, L. Y. (1997). Identification and quantification of major polyphenols in apple pomace. Food Chemistry, 59(2), 187-194. https://doi.org/10.1016/S0308-8146(96)00287-7

Lu, Y., \& Foo, L. Y. (2000). Antioxidant and radical scavenging activities of polyphenols from apple pomace and vegetables. Food Chemistry, 68(1), 81-85. https://doi.org/10.1016/S0308-8146(99)00167-3

Luque de Castro, M. D., \& Garcia-Ayuso, L. E. (1998). Soxhlet extraction of solid materials: An outdated technique with a promising innovative future. Analytica Chimica Acta, 369, 1-10. https://doi.org/10.1016/S0003-2670(98)00233-5

Luque de Castro, M. D., Jiménez-Carmona, M. M., \& Fernández-Pérez, V. (1999). Towards more rational techniques for the isolation of valuable essential oils from plants. TrAC Trends in Analytical Chemistry, 18(11), 708-716. https://doi.org/10.1016/S0165-9936(99)00177-6

Mahawar, M., Singh, A., \& Jalgaonkar, K. (2012). Utility of apple pomace as a substrate for various products: A review. Food and Bioproducts Processing, 90, 597-605. https://doi.org/10.1016/j.fbp.2012.04.007 
Manach, C., Scalbert, A., Morand, C., Rémésy, C., \& Jiménez, L. (2004). Polyphenols: food sources and bioavailability. American Journal of Clinical Nutrition, 79, 727-747. https://doi.org/10.1093/ajen/79.5.727

Monrad, J. K., Howard, L. R., King, J. W., Srinivas, K., \& Mauromoustakos, A. (2010). Subcritical Solvent Extraction of Procyanidins from Dried Red Grape Pomace. Journal of Agricultural and Food Chemistry, 58(7), 4014-4021. https://doi.org/10.1021/jf9028283

Moon, J. K., \& Shibamoto, T. (2010). Formation of volatile chemicals from thermal degradation of less volatile coffee Journal of Agricultural and Food Chemistry, 58, 5465. https://doi.org/10.1021/jf1005148

Nieto, A., Borrull, F., Pocurull, E., \& Marcé, M. (2010). Pressurized liquid extraction: a useful technique to extract pharmaceuticals and personal-care products from sewage sludge. TrAC Trends in Analytical Chemistry, 29(7), 752-764. https://doi.org/10.1016/j.trac.2010.03.014

Ong, E. S., Cheong, J. S. H., \& Goh, D. (2006). Pressurized hot water extraction of bioactive or marker compounds in botanicals and medicinal plant materials: Review. Chromatography. A, 1112, 92-102. https://doi.org/10.1016/j.chroma.2005.12.052

Pérez-Jiménez, J., Arranz, S., \& Saura-Calixto, F. (2009). Proanthocyanidin content in foods is largely underestimated in the literature data: An approach to quantification of the missing proanthocyanidins. Food Research International, 42(10), 1381-1388. https://doi.org/10.1016/j.foodres.2009.07.002

Plaza, M., Abrahamsson, V., \& Turner, C. (2013). Extraction and Neoformation of Antioxidant Compounds by Pressurized Hot Water Extraction from Apple Byproducts. Journal of Agricultural and Food Chemistry, 61, 5500-5510. https://doi.org/10.1021/jf400584f

Plaza, M., Amigo-Benavent, M., Del Castillo, M. D., Ibáñez, E., \& Herroro, M. (2010). Facts about the formation of new antioxidants in natural samples after subcritical water extraction. Food Research International, 43(10), 2341-2348. https://doi.org/10.1016/j.foodres.2010.07.036

Purlis, E. (2010). Browning development in bakery products - A review. Journal of Food Engineering, 99(3), 239-249. https://doi.org/10.1016/j.jfoodeng.2010.03.008

Scalbert, A., \& Williamson, G. (2000). Dietary intake and bioavailability of polyphenols. The Journal of Nutrition, 130(8), 2073S-2085S. https://doi.org/10.1093/jn/130.8.2073S

Schieber, A., Keller, P., \& Carle, R. (2001). Determination of phenolic acids and flavonoids of apple and pear by high- performance liquid chromatography. Chromatography. A, 910, 265-273. https://doi.org/10.1016/S0021-9673(00)01217-6

Shalini, R., \& Gubta, D. K. (2010). Utilization of pomace from apple processing industries: a review. Food Science Technol, 47(4), 365-371. https://doi.org/10.1007/s13197-010-0061-x

Tsao, R., \& McCallum, J. (2009). Chemistry of Flavonoids. In; Eds.; Blackwell Publishing: USA: Ames, IA.

Ulbricht, R., J., Northup, S., J., \& Thomas, J., A. (1984). A Review of 5-Hydroxymethylfurfural (HMF) in Parenteral Solutions. Toxicological Sciences, 4(5), 843-853. https://doi.org/10.1016/0272-0590(84)90106-4

Vasil'ev, Y. I., Morozov, A. N., Zaiko, G. M., \& Moiseeva, V. G. (1976). The utilization of waste from vegetable and fruit canning plants. Konservnaya-i-Ovoshchesushil naya-Promyshlennost, 3, 32-34.

Vendruscolo, F., Albuquerque, P. M., Streit, F., \& Esposito, E. (2008) Apple Pomace: A Versatile Substrate for Biotechnological Applications. Critical. Reviews.in Biotechnology, 28(1), 1-12. https://doi.org/10.1080/07388550801913840

Véronique, C. (2005). Polyphenols in foods are more complex than often thought. Am J Clin Nutr, 81(1), 2235-2295. https://doi.org/10.1093/ajcn/81.1.223S

Vinson, J. A., Su, X., Zubik, L., \& Bose, P. (2001). Phenol antioxidant quantity and quality in foods: fruits. Journal of Agricultural and Food Chemistry, 49, 5315-5321. https://doi.org/10.1021/jf0009293

Wang, L., \& Weller, C. L. (2006). Recent advances in extraction of nutraceuticals from plants. Trends in Food Science \& Technology, 17, 300-312. https://doi.org/10.1016/j.tifs.2005.12.004

Whiting, G. C., \& Coggins, R. A. (1975). Estimation of the monomeric phenolics of ciders. Journal of the Science of Food and Agriculture, 26(12), 1833-1838. https://doi.org/10.1002/jsfa.2740261205

Wijngaard, H. H., \& Brunton, N. (2009). The optimization of extraction of antioxidants from apple pomace by pressurized liquids. Journal of Agricultural and Food Chemistry, 57(22), 10625-10631. https://doi.org/10.1021/jf902498y 
Wijngaard, H. H., \& Brunton, N. (2010). The optimisation of solid-liquid extraction of antioxidants from apple pomace by response surface methodology. Journal of Food Engineering, 96(1), 134-140. https://doi.org/10.1016/j.jfoodeng.2009.07.010

Yue, T., Bai, X., Zhang, H., \& Yuan, Y. (2012). Fractionation and anti-inflammatory effects of polyphenol enriched extracts from apple pomace. Bangladesh Journal of Pharmacology, 7, 28-32. https://doi.org/10.3329/bjp.v7i1.10194

Zhou, Z., Zhang, Y., Ding, X., Chen, S., Yang, J., Wang, X., Jia, G., Chen, H., Bo, X., \& Wang, S. (2007). Protocatechuic aldehyde inhibits hepatitis B virus replication both in vitro and in vivo. Antiviral Research, 74(1), 59-64. https://doi.org/10.1016/j.antiviral.2006.12.005

\section{Copyrights}

Copyright for this article is retained by the author(s), with first publication rights granted to the journal.

This is an open-access article distributed under the terms and conditions of the Creative Commons Attribution license (http://creativecommons.org/licenses/by/4.0/). 